\title{
Geotechnical Modelling for Kimberlite Pipes
}

\author{
D.B. Tyler EKATI Diamond Mine, BHP Billiton, Canada
}

S.J. Godden S. Godden and Associates Ltd, United Kingdom

\begin{abstract}
EKATI Diamond Mine is located some $200 \mathrm{~km}$ south of the Arctic Circle and $300 \mathrm{~km}$ northeast of Yellowknife in the Northwest Territories of Canada. It is a remote fly-in-fly-out site with road access limited to the winter ice road season. The operation currently consists of two active open pits and two underground operations. Feed from the underground mines comprises high-grade material that is vital to the ongoing success of the EKATI operation.

During the Koala Sublevel Caving feasibility study, indicative kriging was used as part of the geotechnical characterisation and modelling process, to aid in the assessment of kimberlite ground conditions, rock mass caveability and ground control requirements. This paper discusses the rational behind key areas of the rock mass characterisation program and how the geotechnical models were developed and verified.
\end{abstract}

\section{Introduction}

The main outcomes of any geotechnical drill core logging program are engineering ratings that should reflect the intact/in situ condition of the rock mass of interest. The results collectively form the basis for geotechnical rock mass characterisations that in turn form a key element of the definition of bulk rock mass modelling constants for engineering analysis and design.

Empirical design solutions can appear attractive because they are easily understood and readily sold, not least because they in general rely on simplification through generalisation of otherwise complex engineering functions. However, the very nature of empirical solutions can result in outcomes that are inevitably conservative and sometimes misleading, especially when they are applied in geotechnical environments that are significantly different from those for which they were originally defined.

Robust methodologies are required to ensure that the outcomes of geotechnical logging programs match the technical requirements of rock mass characterisations, hence the related design programs. Most often the derived engineering functions must be of a type and in a format that allow their use in numerical analysis, if least risk assessments and designs are to be achieved. At Koala, a relationship between moisture content, dry density and material strength was used to develop robust analysis and design tools, including a predictive, three-dimensional model of kimberlite material strength.

\section{Material classification}

An engineering classification of material types was carried out as part of the overall materials' testing program, based on an appreciation of the state of alteration in so-called phase $6 / 7$, primary kimberlite (a variously altered, crystalline kimberlite mass that represents original volcanic material, as distinct from the overlying and re-worked, sedimentary kimberlite series that washed back into the volcanic vent during an extended, post-volcanic period). Distinct groupings of material properties were expected (Godden, 2005), because:

- Unaltered Koala kimberlites typically have fine-grained, crystalline matrices that are olivine-rich.

- Serpentenite and clay are the alteration minerals after olivine, with montmorillonite the dominant clay type (that is hydroscopic).

- Olivine grains in Koala kimberlite typically have serpentenite haloes, except in unaltered phase 7 material. 
- Clay content varies with the severity of alteration that probably occurred in a sub-gaseous environment during emplacement (each kimberlite sub-type represents a mineralogical variant of a single, original kimberlite extrusive material).

- The presence of clay in particular may reasonably be expected to influence peak compressive strengths.

- The density of olivine averages approximately $3500 \mathrm{~kg} / \mathrm{m}^{3}$, the density of serpentenite averages approximately $2500 \mathrm{~kg} / \mathrm{m}^{3}$ and the density of clay averages approximately $1850 \mathrm{~kg} / \mathrm{m}^{3}$.

- There must be correlations between density and mineralogy, density and moisture content and clay content and material strength.

Five main categories of phase 6/7 material were identified following an iterative process of data analysis and review:

- Phase 6 PVK kimberlite that identifies largely unaltered primary volcaniclastic material with a variable olivine content.

- Phase 6 PVKA, PVKB and PVKC that respectively identify slightly, moderately and extensively altered PVK material.

- Phase 7 MK kimberlite located mainly at the base of the known kimberlite mass (which material is essentially wholly unaltered, crystalline and olivine-rich, probably most closely represents the primary volcanic material, but which can also be slightly [MKA], moderately [MKB] and extensively [MKC] altered).

Figure 1 is a scatter plot, referenced to material category, which reflects the anticipated relationship between dry density and moisture content and from which may be construed the anticipated relationships between density and mineralogy. Included on Figure 1 is data for re-sedimented kimberlite (phase 5 RVK) that overlies the phase 6 PVK kimberlites in a remnant volcanic vent. Dry density testing was routinely carried out every six metres along each kimberlite drill core intersection that, including the samples used for material strength testing, provided a total of 724 data points.

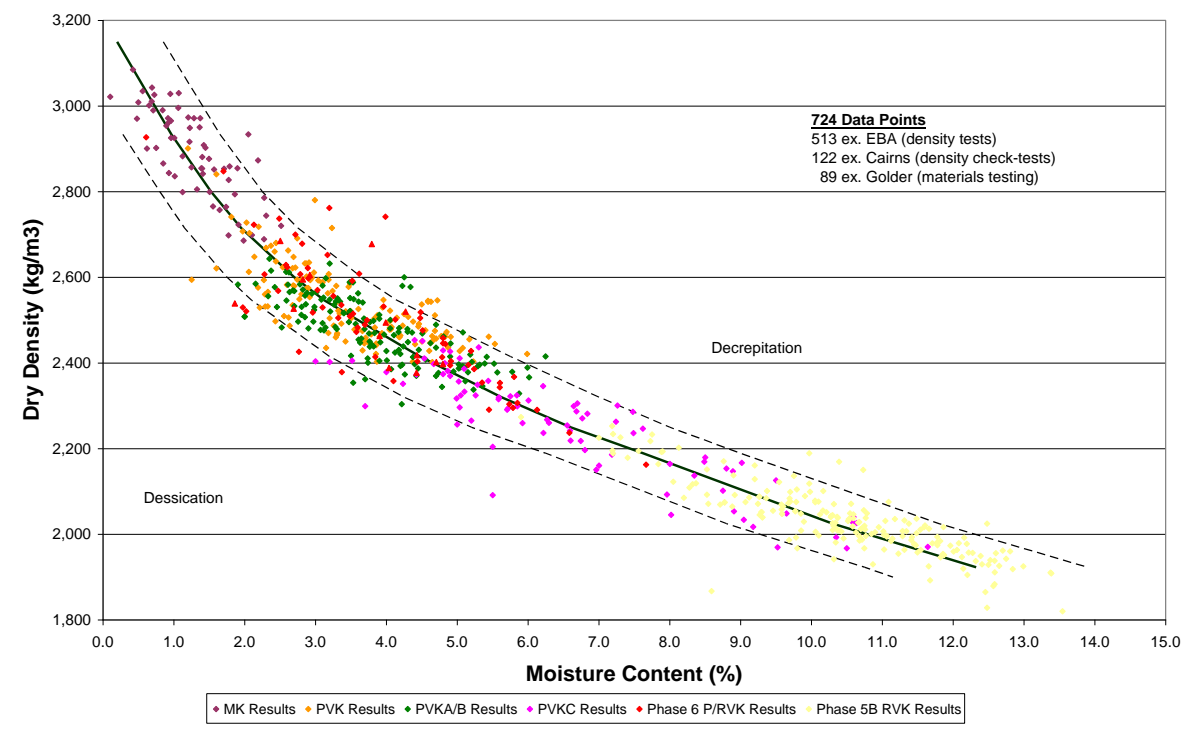

Figure 1 A scatter plot of dry density versus moisture content, Koala phase 6/7 kimberlites

\section{Behavioural characteristics}

Analysis of the database of uniaxial and triaxial compressive strengths for phase $6 / 7$ kimberlites showed that the results matched expectations, in so far as distinct differences in the strength ranges were reported for unaltered (PVK and MK, which reported almost exactly the same results), slightly altered (PVKA) and 
extensively altered (PVKC) material (Godden, 2005). Figure 2 demonstrates this - it is a combined scatter and line plot that summarises the validated strength data for PVK+MK, PVKA and PVKC materials and attributes various Hoek-Brown strength envelopes to the data:

- The average strength envelope for MK + PVK material is representative of both PVK and MK material.

- The upper strength envelope for altered PVK defines the maximum strength for PVKA material and the lower strength envelope for altered PVK defines the minimum strength envelope for PVKC material.

- The average of the maximum and minimum strength curves defines the strength curve for average PVKB, as well as the overall average strength curve for altered PVK material.

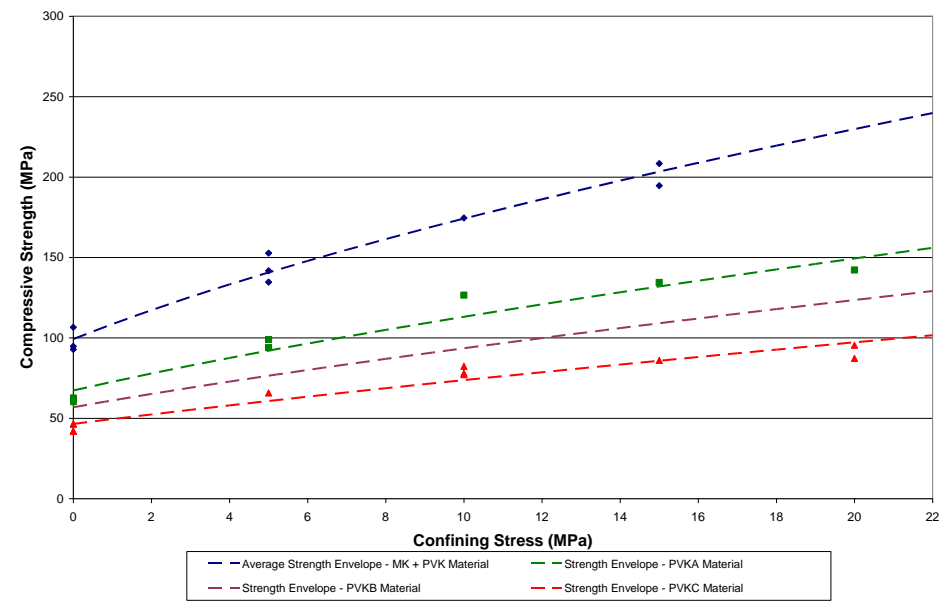

Figure 2 Validated compressive strength test data and intact strength envelopes for Koala phase 6/7 kimberlite

The commercially available program ROCKDATA (ROCKDATA, 1991), incorporating the Simplex Reflection technique (Shah and Hoek, 1992) was used for the determination of Hoek-Brown constants for intact rock, hence Hoek-Brown strength envelopes for each phase 6/7 kimberlite type. This was deemed appropriate because, in common with the vast majority of rocks, phase 6/7 kimberlites may be described as brittle, linear elastic materials (Obert and Duvall, 1967). Their brittle nature is reflected in their mode of fracturing on compression (single, well-defined shear planes), their post-peak stress-strain performance (dynamic load shedding on failure) and their behaviour underground (where brittle sidewall failure may be observed in excavations subjected to critical levels of applied total stress).

Figure 3 summarises stress-strain curves for MK, PVK, PVKA and PVKC material, established as part of the Koala compression testing program. Linear elasticity may be construed from the presented results, or at least it may be concluded that each of the tested materials has a stress-strain relationship that is sufficiently close to linear elasticity as to make little or no difference.

\subsection{Data analysis}

Standard solutions for defining strength envelopes (Hoek et al., 2002), hence average intact material properties for brittle, linear elastic materials, by definition assume progressive increases in peak strength with increasing confining stress. Consideration of the results summarised in Figure 2 shows this assumption to be entirely appropriate in the case of PVK/MK material. However, each of the strength curves for altered PVK:

- Slightly over-estimate the materials' strengths in uniaxial compression but slightly under-estimate the materials' strengths at confining pressures of less than about $15 \mathrm{MPa}$.

- Predict well the materials' strengths at confining pressures of about $15 \mathrm{MPa}$ but again over-estimate the materials' strengths at confining pressures greater than about $15 \mathrm{MPa}$. 


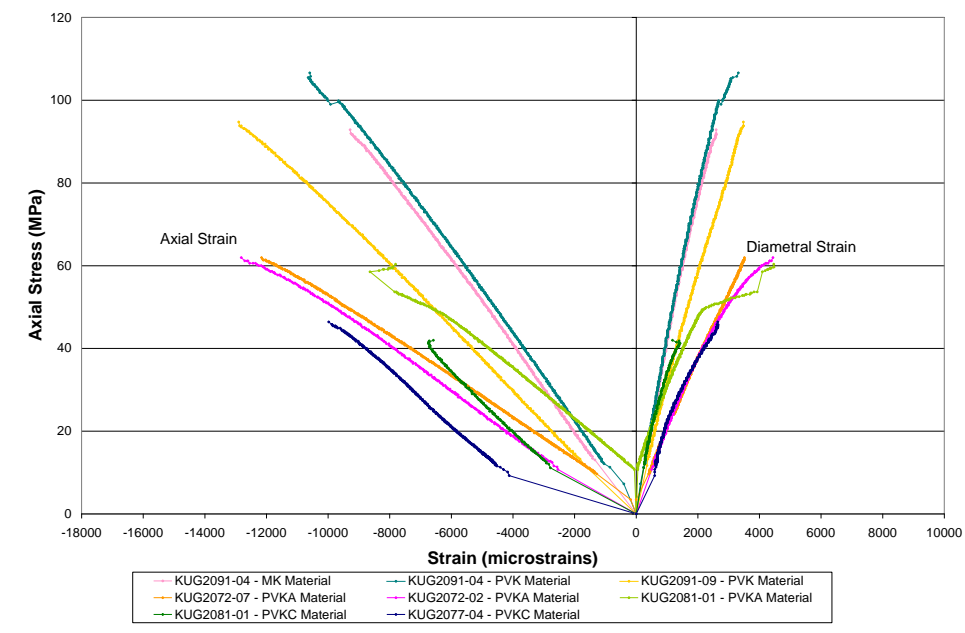

\section{Figure 3 Stress-strain curves for Koala phase 6/7 kimberlite}

\subsection{Brittle-ductile transitions}

The trends outlined typify the onset of the brittle-ductile transition for the tested material types (Obert and Duvall, 1967). All brittle materials in theory reach the brittle-ductile transition at some confining stress that is unique for each material type, which in rare cases is not even reached during major tectonic events. However, field evidence (Godden, pers. comm. 2006) shows clearly that bulk in situ ductile deformation of rock masses can occur, as evidenced by the in situ presence of ubiquitous micro-fracturing resulting in strongly non-linear stress-strain curves and much reduced average compressive strengths. Figure 4 suggests that the brittle-ductile transition for PVKC material starts at a confining pressure of about $15 \mathrm{MPa}$ and for PVKA material at an estimated confining pressure of about $20 \mathrm{MPa}$. In either case it is the onset of the flat portion of the strength envelope that marks the onset of the ductile deformation phase.

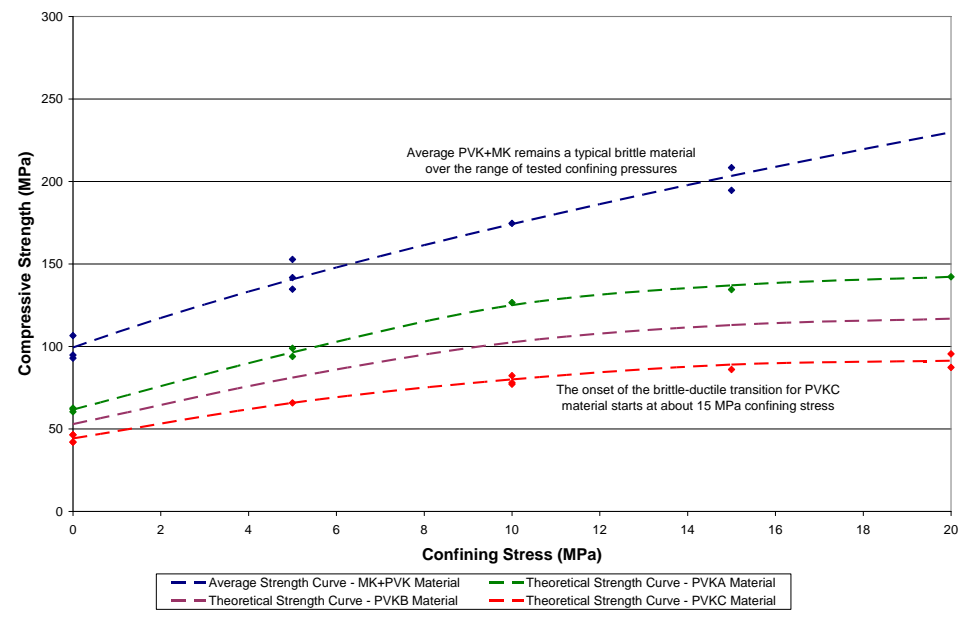

Figure 4 Adjusted/theoretical strength curves for altered phase 6 material

\subsection{In situ performance}

Explanations such as elasto-plastic deformation, plastic deformation and even creep have been offered to describe the bulk in situ behaviour of kimberlite, based on observed large-scale displacements in overstressed excavations. Plastic deformation and creep are distinct behavioural types that apply to materials such as pitch and plasticine only (plastic behaviour) and non-linear, visco-elastic materials such as halite and potash only (creep). Large-scale deformation in kimberlite is, instead, a manifestation of irresistible, ductile deformation that can extend over large distances from a deforming excavation, depending on the state of 
stress and the volume available into which rock mass deformation can occur. In some cases, deformation can extend for over $25 \mathrm{~m}$ from an excavation boundary where it can be marked by tear-apart/tension gashing (Godden, 2005).

In other words, if the magnitudes of the applied stress state acting around an excavation hosted in kimberlite were less than those required to induce ductile behaviour, the kimberlite would behave in a conventional, brittle manner. This does not, however, necessarily infer slab-type wallrock failure - the intensity of fracturing is in part dependent on the modulus of the loaded material (Obert and Duvall, 1967). In the case of kimberlite very close fracturing may reasonably be expected whereas in the case of medium grained igneous rocks that have comparatively high moduli, more conventional, large-slab type failure can be expected. In either case, analysis shows that the onset of sidewall failure can be expected when the magnitude of applied total stress acting around the periphery of a cut excavation approximates to 35\% of the uniaxial compressive strength of the rock (Godden, 2006).

\subsection{Challenges}

Confining pressures in excess of $15 \mathrm{MPa}$ are expected during the life of Koala underground mine, with the result that altered PVK material may reasonably be expected to deform without constraint if some critical field stress condition is reached. This can place unique constraints on drift support systems and it may be argued that such behaviour can in theory place a practical depth limit on safe and cost effective mining.

Detailed analyses and drift support designs based on ductile behavioural models were not requested as part of the scope of the Koala feasibility study (Ekati, 2006) - robust costings, for the expected kimberlite drift support systems only, were required for input into financial models. The results of multi-phase triaxial testing to define both pre- and post-peak deformation characteristics of kimberlite are required as part of the data package for analytic, non-linear rock mass modelling. The method also relies on instrumentation results to verify assumptions and to calibrate the computer models.

\section{Material properties}

Despite the onset of ductile behaviour and for the reasons outlined, industry standard numerical solutions were applied to define average intact material properties for phase $6 / 7$ kimberlites, over the brittle range of their stress-strain curves. Table 1 summarises the results, inclusive of the elastic constants defined from the stress-strain curves summarised on Figure 4.

Table 1 Average intact material properties, phase 6/7 kimberlite

\begin{tabular}{lccccccc}
\hline \multirow{2}{*}{ Material } & \multicolumn{2}{c}{ Elastic Constants } & \multicolumn{2}{c}{$\begin{array}{c}\text { Shear Strength } \\
\text { Parameters }\end{array}$} & \multicolumn{2}{c}{ Hoek-Brown Constants } \\
\cline { 2 - 8 } & $\mathrm{E}_{\mathrm{m}}(\mathrm{GPa})$ & $v$ & $\mathrm{C}_{\mathrm{o}}(\mathrm{MPa})$ & $\varnothing$ & $\mathrm{m}$ & $\sigma_{\mathrm{c}}(\mathrm{MPa})$ & $\sigma_{\mathrm{t}}(\mathrm{MPa})$ \\
\hline PVK+MK & 10.5 & 0.26 & 19.6 & $48.3^{\circ}$ & 17.21 & 99.3 & -5.8 \\
PVKA & 5.5 & 0.28 & 16.3 & $38.7^{\circ}$ & 9.07 & 67.3 & -7.3 \\
PVKB & 5.0 & 0.23 & 16.1 & $32.5^{\circ}$ & 6.58 & 56.9 & -8.5 \\
PVKC & 4.5 & 0.18 & 15.2 & $25.2^{\circ}$ & 4.09 & 46.5 & -10.7 \\
\hline
\end{tabular}

\subsection{Rock mass ratings}

Rock mass ratings (Bieniawski, 1976) were defined for each phase 6/7 kimberlite type, which in itself created various technical challenges. For example:

- Rock mass ratings should report average values for an intact, in situ rock mass.

- Decrepitation of drill core intersections of altered PVK material in general started during the drilling process (water was used as the basis for the drilling lubricant) and continued when water was added to clean the core prior to both geological and geotechnical logging. 
- The strength values determined for core samples during the geotechnical logging phase were assessed to not fairly reflect the intact, in situ strength of the rock.

- RQD values were defined separately from the assessed strength of core samples during the logging process, from considerations of the likely in situ condition of the rock mass as a whole.

- The strength and RQD values stated on Table 2 were applied.

Table 2 Average Koala phase 6/7 kimberlite rock mass ratings $\left(\mathrm{RMR}_{\mathbf{7 6}}\right)$

\begin{tabular}{lcccc}
\hline \multirow{2}{*}{ Parameter } & \multicolumn{4}{c}{ Phase 6/7 Material } \\
\cline { 2 - 5 } & $\begin{array}{c}\text { MK and } \\
\text { PVK }\end{array}$ & PVKA & PVKB & PVKC \\
\hline UCS & 8 & 5.5 & 5 & 4 \\
RQD & 19 & 19 & 18.5 & 18 \\
Spacing of joints & 30 & 30 & 29 & 28 \\
Condition of joints & 25 & 25 & 25 & 25 \\
Groundwater & 10 & 10 & 10 & 10 \\
Joint orientation & 0 & 0 & 0 & 0 \\
\hline Totals & 92 & 89.5 & 87.5 & 85 \\
\hline
\end{tabular}

In all, a total of 283 joints and joint clusters/joint zones were identified in the Koala kimberlite from a total of $3790 \mathrm{~m}$ of kimberlite drilled during the feasibility study program (3168 m of phase $6 / 7$ material, excluding granodiorite xenoliths). The identified joints were interpreted as cooling features with random orientations and sometimes strongly curved surfaces, based on considerations of the joint plane characteristics (roughness, infilling, etc.), the nature and distribution of joint planes observed underground and the results of detailed structural analysis. Despite this, the RQD values for altered PVK material were reduced to reflect the theoretical possibility of slightly increased discontinuity densities in these comparatively weak portions of the kimberlite mass.

Figure 5 provides an illustration of the types of strength-reducing effects the addition of water to altered/swelling clay-rich kimberlites could have (Godden, 2005).

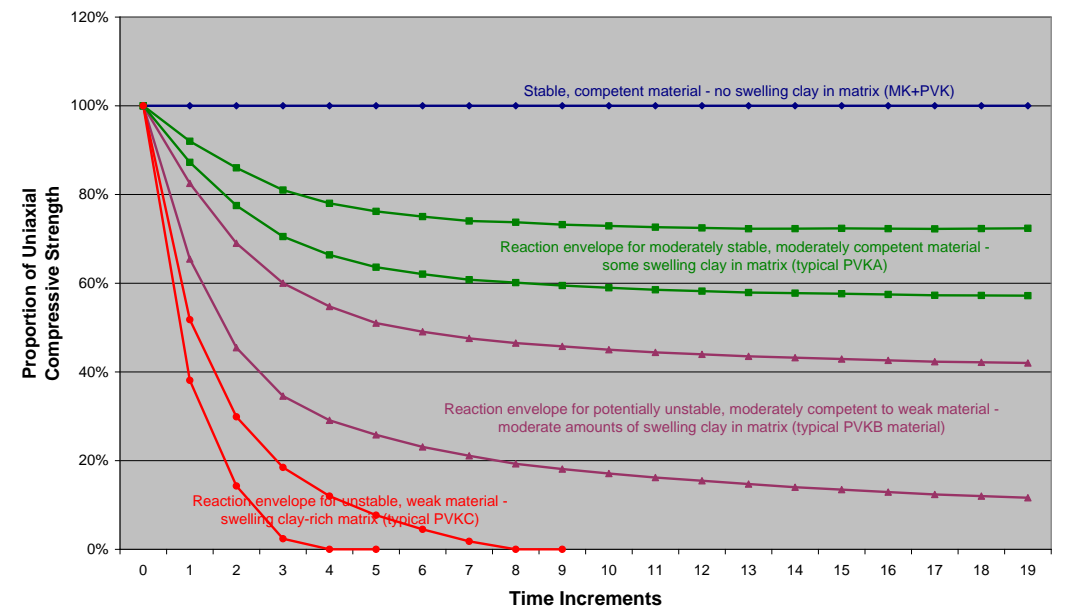

Figure 5 Conceptual strength-time reaction curves for kimberlites subjected to moisture

It may be seen that sometimes rapid degradation of altered kimberlite can occur, which effect is reflected in the sometimes disaggregated lengths of fully decrepitated (PVKC) material soon develop after the drill core is laid out in its core box (Figure 6). 


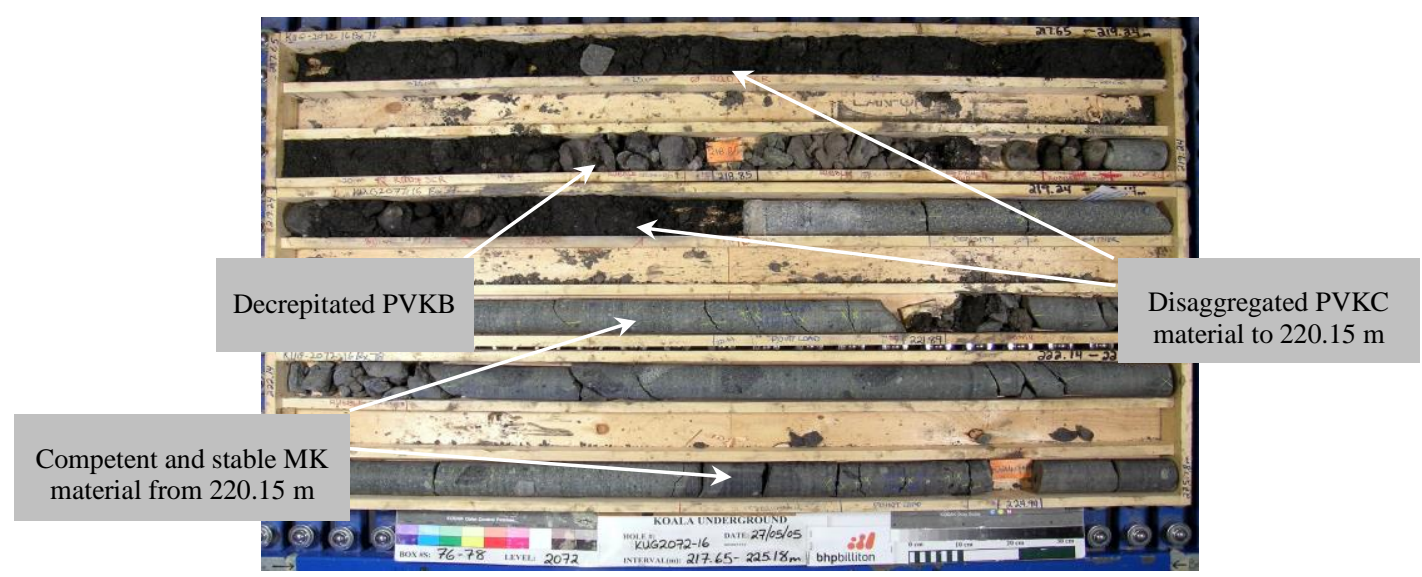

Figure 6 An example of disaggregated and stable PVK materials

\subsection{Bulk in situ material properties}

Linear elastic theory depends on the application of Hooke's Law (Obert and Duvall, 1967), hence the use of bulk in situ elastic constants for application in global field stress analysis. For purposes of assessing rock mass failure potential, one or both of the following groups of bulk in situ modelling constants is required for each category of engineering material type: Mohr-Coulomb parameters (cohesion and friction angle) and average uniaxial tensile strength; or Hoek-Brown parameters (the constants ' $\mathrm{m}_{\mathrm{b}}$ ' and ' $\mathrm{sb}$ ') and the average uniaxial compressive strength for the bulk rock mass (the constant $\sigma_{\text {cmass }}$ ).

Bulk in situ rock mass stiffness may be approximated by application of equivalent rock mass stiffness, of which Young's modulus is a measure. Equivalent rock mass stiffness varies with the stiffness of intact rock and the average normal stiffness of the contained discontinuities, or series of discontinuities, normal to the plane/s of their average trend/s. In the absence of any persistent parting planes, this relationship may be approximated by applying Goodman's equation (Goodman, 1989). Poisson's ratios for intact rock do not require adjustment. Table 3 summarises the relevant results.

Table 3 Summary of assumed average rock mass modelling constants

\begin{tabular}{|c|c|c|c|c|c|c|c|c|}
\hline \multirow[b]{2}{*}{$\begin{array}{l}\text { Material } \\
\text { Type }\end{array}$} & \multicolumn{2}{|c|}{$\begin{array}{l}\text { Elastic } \\
\text { Constants }\end{array}$} & \multicolumn{2}{|c|}{$\begin{array}{l}\text { Shear Strength } \\
\text { Parameters }\end{array}$} & \multicolumn{2}{|c|}{$\begin{array}{l}\text { Hoek-Brown } \\
\text { Constants }\end{array}$} & \multicolumn{2}{|c|}{$\begin{array}{l}\text { Rock Mass } \\
\text { Parameters }\end{array}$} \\
\hline & $\begin{array}{c}\mathrm{E}_{\mathrm{m}} \\
(\mathrm{GPa})\end{array}$ & $v$ & $\begin{array}{c}\mathrm{C}_{\mathrm{o}} \\
(\mathrm{MPa})\end{array}$ & $\varnothing$ & $\mathrm{m}_{\mathrm{b}}$ & $\mathrm{S}_{\mathrm{b}}$ & $\begin{array}{c}\sigma_{\text {cmass }} \\
(\mathrm{MPa})\end{array}$ & $\begin{array}{c}\sigma_{\text {tmass }} \\
(\mathrm{MPa})\end{array}$ \\
\hline $\mathrm{PVK}+\mathrm{MK}$ & 9.5 & 0.26 & 13.35 & $46.93^{\circ}$ & 12.93 & 0.411 & 63.65 & -3.16 \\
\hline PVKA & 5.0 & 0.28 & 8.53 & $40.23^{\circ}$ & 6.23 & 0.311 & 37.54 & -3.36 \\
\hline PVKB & 4.5 & 0.23 & 6.84 & $36.75^{\circ}$ & 4.28 & 0.249 & 28.39 & -3.32 \\
\hline PVKC & 4.0 & 0.18 & 5.32 & $31.27^{\circ}$ & 2.39 & 0.189 & 20.18 & -3.67 \\
\hline
\end{tabular}

The Mohr-Coulomb parameters and Hoek-Brown constants summarised on Table 3 were defined by applying numerical solutions established by Hoek (1990). The results may be realised through the use of the commercially available program Rocscience (2002), by setting the Disturbance Factor 'D' to zero and by applying for each material or material group of interest:

- Its average uniaxial compressive strength and Hoek-Brown constant ' $\mathrm{m}$ ' for intact rock.

- The assessed average $\mathrm{RMR}_{76}$ value for the bulk in situ rock (termed 'GSI' in ROCLAB, which emphasises the importance of defining $\mathrm{RMR}_{76}$ values, rather than other variants that are not incorporated in main stream rock engineering). 


\subsection{Modelling constants}

An understanding of the distribution of material types within a variable kimberlite mass is important in excavation stability analysis, especially if low strength/altered kimberlite types exist. This is not, however, necessarily the case when considering global field stress analysis:

- It is the bulk deformation characteristics of the rock mass that are of interest.

- Reality cannot be modelled, in so far as all possible variations in material type throughout a rock mass of interest cannot either be defined or simulated - a series of approximations instead have to be applied.

- In any event, local/minor changes in material type are unlikely to have significant impacts on the distributions and magnitudes of field stress, especially if the material types are intimately mixed.

- For most practical purposes, it is reasonable to ascribe one set of material constants for purposes of computer-based analysis.

Two methods were applied to assess the relative frequencies of the five categories of Koala phase 6/7 kimberlite types: analysis of material types by sample frequency (density/moisture content samples only); and analysis of material types by drill core intersection length (Godden, 2006). An iterative process was employed:

- Drill core intersections were categorised by reference to the database of test results (compressive strengths, dry density and moisture content) and by, comparison of these results with the geological and geotechnical descriptions contained within the drill core logs, backed by scrutiny of the photologs for the same drill core intersections.

- Individual samples were cross-referenced to the categorised drill core intersections and then compared with material type expectations, based on their densities, moisture contents and expected material strengths.

- The process was continued and the resultant material type categorisations refined until the total database of test results (724 samples, including 204 samples of phase 5 RVK material and 69 compression test results) could be fully verified and robustly attributed to a specific phase $6 / 7$ material category.

Table 4 summarises the results by overall sample frequency and drill core intersection lengths. By combining the results, the following overall average frequencies were defined: $\mathrm{PVK}+\mathrm{MK}-40 \%$; PVKA/B + MKA/B 40\%; and PVKC + MKC - 20\% (Godden, 2006). The A and B categories of phase 6/7 kimberlite alteration were combined as it proved impossible to routinely separate them the drill core intersections - albeit that different data sets of density, moisture and compressive strength could be defined.

Table 4 Summary of phase 6/7 density sample and drill core intersection frequencies

\begin{tabular}{lccccccc}
\hline & \multicolumn{7}{c}{ Material Type } \\
Data Source & MK & MKA/B & MKC & PVK & PVKA/B & PVKC & Totals \\
\hline Total samples & 56 & 59 & 4 & 138 & 125 & 69 & 451 \\
\% of overall total & $12.4 \%$ & $13.1 \%$ & $0.9 \%$ & $30.6 \%$ & $27.7 \%$ & $15.3 \%$ & $100 \%$ \\
Total intersection length & 359.2 & 154.6 & 31.3 & 857.3 & 1091.3 & 674.9 & $3168.6 \mathrm{~m}$ \\
\% of overall total & $11.3 \%$ & $4.9 \%$ & $1.0 \%$ & $27.1 \%$ & $34.4 \%$ & $21.3 \%$ & $100 \%$ \\
\hline
\end{tabular}

Although the results outlined could justifiably be applied to determine weighted average, bulk in situ modelling constants for the overall kimberlite mass (Table 5), the results of spatial analysis of material types showed that a significant proportion of PVKC material and a significant amount of PVKA/B material identified in the drill core intersections occurs towards the top of the phase 6/7 kimberlite domain (Godden, 2006). Most of the PVK+MK material identified in the drill core intersections was also found to occur towards the centre and middle of the phase 6/7 kimberlite domain. 
The preceding points had important implications within the context of rock mass caveability, for which reason the average bulk in situ properties for the phase 6/7 kimberlite mass above the first production level on $2050 \mathrm{~mL}$ were estimated from the results of indicative kriging (IK) described below. The following estimated frequencies of material types were in this case found to apply: $\mathrm{PVK}+\mathrm{MK}-26 \%$; PVKA/B + MKA/B - 54\%; and PVKC + MKC - 20\% (Godden, 2006). The resultant, weighted bulk in situ material properties used for purposes of phase $6 / 7$ caveability assessments above $2050 \mathrm{~mL}$ are summarised on Table 5.

\section{Table 5 Summary of phase $6 / 7$ bulk in situ modelling constants}

\begin{tabular}{|c|c|c|c|c|c|c|c|c|}
\hline \multirow[b]{2}{*}{$\begin{array}{l}\text { Phase 6/7 Rock } \\
\text { Mass }\end{array}$} & \multicolumn{2}{|c|}{$\begin{array}{c}\text { Elastic } \\
\text { Constants }\end{array}$} & \multicolumn{2}{|c|}{$\begin{array}{l}\text { Shear Strength } \\
\text { Parameters }\end{array}$} & \multicolumn{2}{|c|}{$\begin{array}{l}\text { Hoek-Brown } \\
\text { Constants }\end{array}$} & \multicolumn{2}{|c|}{$\begin{array}{l}\text { Rock Mass } \\
\text { Parameters }\end{array}$} \\
\hline & $\begin{array}{c}\mathrm{E}_{\mathrm{m}} \\
(\mathrm{GPa})\end{array}$ & $\mathrm{v}$ & $\begin{array}{c}\mathrm{C}_{\mathrm{o}} \\
(\mathrm{MPa})\end{array}$ & $\varnothing$ & $\mathrm{m}_{\mathrm{b}}$ & $\mathrm{Sb}_{\mathrm{b}}$ & $\begin{array}{l}\sigma_{\text {cmass }} \\
(\mathrm{MPa})\end{array}$ & $\begin{array}{c}\sigma_{\text {tmass }} \\
(\mathrm{MPa})\end{array}$ \\
\hline Overall rock mass & 6.5 & 0.24 & 9.14 & $41.92^{\circ}$ & 7.36 & 0.301 & 40.52 & -3.02 \\
\hline Above $2050 \mathrm{~mL}$ & 6.0 & 0.24 & 8.40 & $40.56^{\circ}$ & 6.36 & 0.285 & 36.65 & -3.08 \\
\hline
\end{tabular}

\section{Spatial distribution of kimberlite types}

The results by drill core intersection were eventually compiled in an Excel spreadsheet format suitable for application in VULCAN. The kimberlite material types were individually coded and presented as colourcoded cylinders wrapped around data-relevant drillhole traces. Figure 7 provides an example of this.

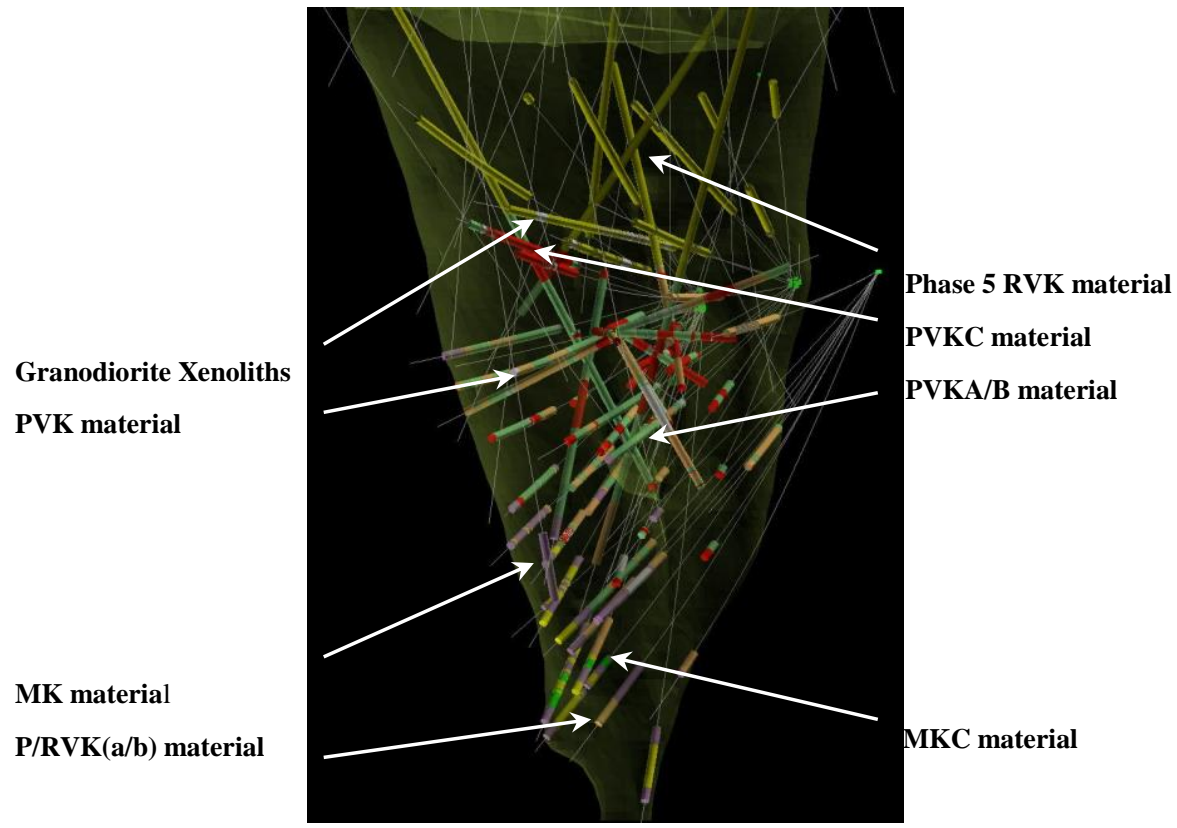

Figure 7 A snapshot of the distribution of kimberlite material types, looking north

The base data for the IK model comprised the feasibility drillhole database (drillhole collars, lengths, azimuths and dips); the orebody profile was compiled by BHP Billiton Diamond's Geology Department. Each drill core intersection was characterised according to engineering material type, where Group $1=\mathrm{PVK}+\mathrm{MK}$ material, Group $2=\mathrm{PVKA} / \mathrm{B}+\mathrm{MKA} / \mathrm{B}$ (combined for the reasons earlier outlined) and Group $3=\mathrm{PVKC}+\mathrm{MKC}$, plus granodiorite xenoliths defined as Group 4. A minimum intersection length of $1 \mathrm{~m}$ was employed. The material type intervals with drill core intersection lengths of less than $1 \mathrm{~m}$ were amalgamated with an adjacent, $>1 \mathrm{~m}$ intervals. If both adjacent $>1 \mathrm{~m}$ intervals comprised the same material type, all three intervals were combined to form a single (modelled) interval. If different material types applied to the adjacent $>1 \mathrm{~m}$ interval then $<1 \mathrm{~m}$ interval was combined with the lower category/weaker $>1 \mathrm{~m}$ interval, as Table 6 suggests. 
Table 6 Summary of phase 6/7 kimberlite intersections, KUG2050-05

\begin{tabular}{cccccc}
\hline \multicolumn{3}{c}{ Logged/Assessed As } & \multicolumn{3}{c}{ Modelled As } \\
Interval (m) & Length (m) & Material Type & Interval (m) & Length (m) & Material Group \\
\hline $00.00-05.00$ & 5.00 & PVKC & $00.00-05.00$ & 05.00 & 3 \\
$05.00-12.35$ & 7.35 & PVK & $05.00-27.00$ & 22.00 & 1 \\
$12.35-12.80$ & 0.45 & Xenolith & $\downarrow$ & - & - \\
$12.80-27.00$ & 14.20 & PVK & $\downarrow$ & - & - \\
$27.00-31.21$ & 4.21 & PVKA/B & $27.00-33.07$ & 06.07 & 2 \\
$31.21-32.07$ & 0.86 & Xenolith & $\downarrow$ & - & - \\
$32.07-33.07$ & 1.00 & PVKA/B & $\downarrow$ & - & - \\
$33.07-63.02$ & 29.95 & Xenolith & $33.07-63.02$ & 29.95 & 4 \\
\hline
\end{tabular}

\subsection{Variography}

Variography was used to define the search ellipse and to create a variogram model for use in IK simulation. $20 \mathrm{Lags}$ and a lag size of $10 \mathrm{~ms}$ in all directions were used to create indicator semi-variograms, from which a variogram map was created. The same lag size and number of lags were applied to each material category when running the variography, to minimise bias of any one material category. The variogram map was used to establish the major, semi-major and minor directions required for directional variography, the results of which were in turn used to create a variogram model (Godden, 2006). The results are summarised on Table 7.

Table 7 Summary of variography results, Koala phase 6/7 IK Model

\begin{tabular}{|c|c|c|c|c|c|c|c|c|c|}
\hline \multirow{2}{*}{ Category } & \multirow{2}{*}{ Nugget } & \multirow{2}{*}{ Variance } & \multirow{2}{*}{$\begin{array}{c}\text { Sill } \\
\text { Diff. }\end{array}$} & \multicolumn{3}{|c|}{ Range } & \multirow{2}{*}{ Bearing } & \multirow{2}{*}{ Plunge } & \multirow{2}{*}{ Dip } \\
\hline & & & & Major & Semi-Major & Minor & & & \\
\hline 1 & 0.038 & 0.21700 & 0.179 & $74.63 \mathrm{~m}$ & $48.02 \mathrm{~m}$ & $106.00 \mathrm{~m}$ & $126^{\circ}$ & $8^{\circ}$ & $0^{\circ}$ \\
\hline 2 & 0.215 & 0.23942 & 0.048 & $146.00 \mathrm{~m}$ & $125.00 \mathrm{~m}$ & $67.70 \mathrm{~m}$ & $269^{\circ}$ & $-13^{\circ}$ & $26^{\circ}$ \\
\hline 3 & 0.170 & 0.16952 & 0.005 & $6.92 \mathrm{~m}$ & $5.74 \mathrm{~m}$ & $3.08 \mathrm{~m}$ & $23^{\circ}$ & $-9^{\circ}$ & $-27^{\circ}$ \\
\hline 4 & 0.056 & 0.06284 & 0.005 & $88.80 \mathrm{~m}$ & $19.80 \mathrm{~m}$ & $16.20 \mathrm{~m}$ & $216^{\circ}$ & $-14^{\circ}$ & $-45^{\circ}$ \\
\hline
\end{tabular}

\subsection{Block model}

A block model (rib-normalised) was created with a parent block size of $5 \times 5 \times 5 \mathrm{~m}$, to honour the planned drift and stope block dimensions to the nearest $0.5 \mathrm{~m}$. A sub-block size of $1 \mathrm{x} 1 \mathrm{x} 1 \mathrm{~m}$ was used to honour the minimum drill core intersection length assumed in analysis. The simulated blocks were constrained within the defined orebody envelope.

\subsection{IK simulation}

An IK approach was used to assign values to the variables that populated the block model; each category was in turn simulated to produce a resultant probability of each material category populating each modelled block. Minimum and maximum sample counts of four and 20, respectively, were used for each material category and the category variables were transformed into a cumulative distribution function.

\subsection{Confidence levels}

The simulation method outlined yields percent probabilities for each material category for each simulated block. As such, and depending on the local variability of the kimberlite orebody and/or the density of 
available data around any simulated block, individual blocks can report the presence of one or more material categories - some might even report all four. However, only the dominant material category, as defined by the percent probability of its presence within any selected block, is reported in the data outputs. As such, the reported results define best estimates for each simulated block.

Four levels of confidence were applied initially to facilitate results' analysis (Godden, 2006):

- $>90 \%$ probability of a single material category populating any simulated block of interest (which reflects a high confidence that the result is real).

- $75 \%$ to $90 \%$ probability that suggests a moderate or medium level of confidence that the reported result is real.

- $50 \%$ to $74 \%$ probability that suggests that a low level of confidence should be applied to the reported result.

- $\quad<50 \%$ probability that suggests that little or no confidence should be placed in the reported result (i.e. the simulated block could in reality contain two or more of the four material categories).

Sixteen different outcomes were possible within any single block (i.e. four material categories times four confidence limits for each material category). To facilitate analysis, the outcomes were colour-coded on confidence level plans for each production level. For example, on $1990 \mathrm{~mL}$ :

- The BUFF coloured blocks (Figure 8) reflect those blocks for which a low confidence level applies to the Category 2 material attributions (i.e. the IK model suggests that there is a $75 \%$ to $90 \%$ probability that the blocks contain PVKA/B+MKA/B material).

- The MAGENTA coloured blocks reflect those blocks for which a low confidence level that the material contain within the blocks comprises Category 1 material (i.e. the IK model predicts there is a $50 \%$ to $75 \%$ probability that the blocks contain $\mathrm{PVK}+\mathrm{MK}$ material.

- The LIGHT BLUE coloured blocks, within the defined orebody boundary, reflect those blocks for which no confidence can be placed in the defined blocks containing any particular material category (i.e. the IK model suggests that none of the calculated probabilities exceeds $50 \%$ for any of the four material categories considered in analysis).

\subsection{Best estimates}

As earlier noted, VULCAN IK model outputs assume that the material category with the highest attributed probability defines the best estimate result. As such, any probability result that reports within the low, medium or high levels of confidence automatically defaults to the best estimate result for the material type to which it applies. In other words, for the $1900 \mathrm{~mL}$ example:

- The best estimate for the BUFF coloured blocks is by default Category 2 material (i.e. PVKA/B+MKA/B).

- The best estimate result for the MAGENTA coloured blocks is by default Category 1 material (i.e. $\mathrm{MK}+\mathrm{PVK}$ ).

The interpretation of the best estimate result for the LIGHT BLUE orebody blocks is more complex because two or more possible results might apply. For example, the VULCAN IK model might:

- For one highlighted block report probabilities of $41.5 \%$ for Category 1 material, $35 \%$ for Category 2 material, $21.5 \%$ for Category 3 material and $2 \%$ for xenoliths, in which case the balance of probabilities suggests that the material within the simulated block is Category 1 (i.e. PVK+MK) and the best estimate result would report as such.

- For a different, adjacent block different probabilities might yield a different best estimate result, thereby resulting is a mosaic of different outcomes. 


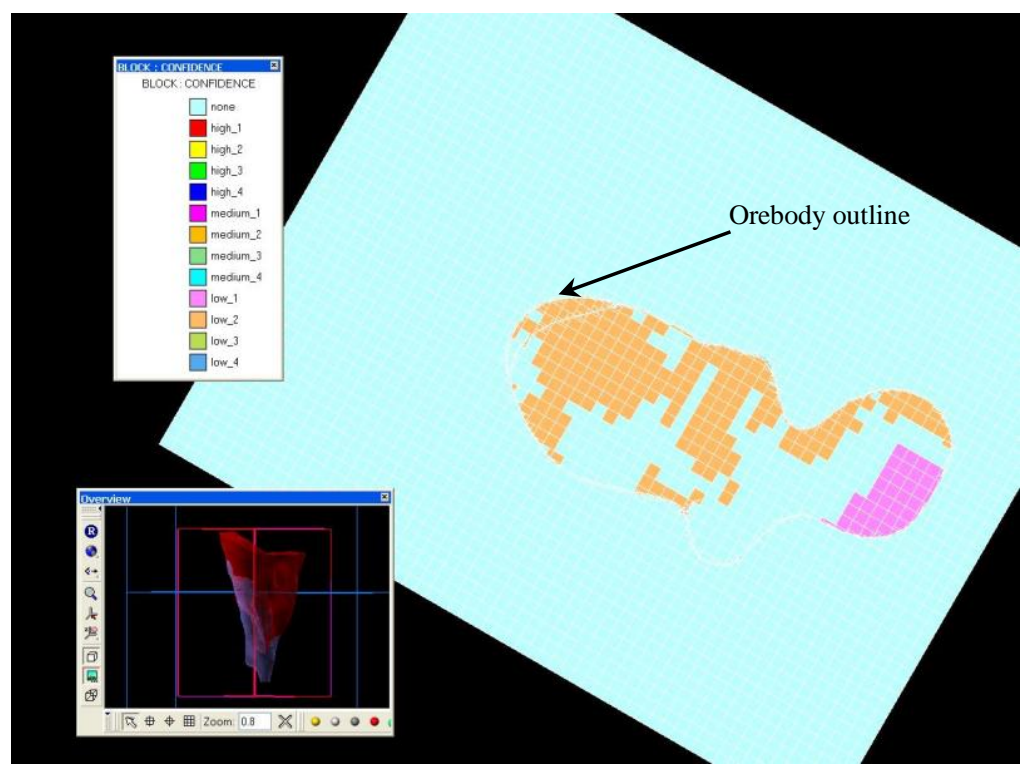

Figure 8 VULCAN IK confidence levels output, $1990 \mathrm{~mL}$

Depending on the density of input data/drillhole spacings, a significant number of no confidence blocks might exist. However, this might be resolved by applying small changes to the defined confidence levels and by re-running the IK model. For Koala, a second cycle of IK analysis was run with the script for the no confidence category modified to include the following statement: if the confidence level is more than $35 \%$ but less than $50 \%$ and the difference in the reported confidence level between the two categories is less than five per cent, the best estimate result should default to the weaker material type.

\subsection{Results}

For purposes of feasibility analysis, single block slices were taken at each planned SLC production level and the amount by volume calculated for each material category. The floor elevations of the block slices matched the planned floor elevations of the SLC production levels. The results of the two cycles of analysis, for the first few production levels, are summarised on Table 8 (Godden, 2006).

It may be concluded from consideration of the presented results that the second cycle of results uniformly reflects better average/higher category ground than the first cycle of results. This suggests that the average ground conditions might be better than the first cycle results suggest, but to conform to the reasonable assumption of average worst case for purposes of predictive stability analysis, the first cycle of tests were assumed for purposes of stability analysis and support design.

Table 8 Summary of occurrence of material categories by volume and production level

\begin{tabular}{ccccccccc}
\hline & \multicolumn{3}{c}{ First IK Cycle Results } & \multicolumn{3}{c}{ Second IK Cycle Results } \\
\cline { 2 - 9 } Level & One & Two & Three & Xenoliths & One & Two & Three & Xenoliths \\
\hline 2070 & $18.9 \%$ & $33.6 \%$ & $47.5 \%$ & $0.0 \%$ & $36.1 \%$ & $30.5 \%$ & $33.5 \%$ & $0.0 \%$ \\
2050 & $15.6 \%$ & $63.0 \%$ & $21.3 \%$ & $0.1 \%$ & $29.4 \%$ & $56.1 \%$ & $14.4 \%$ & $0.1 \%$ \\
2030 & $23.0 \%$ & $50.4 \%$ & $26.6 \%$ & $0.0 \%$ & $39.0 \%$ & $47.0 \%$ & $14.0 \%$ & $0.0 \%$ \\
2010 & $14.7 \%$ & $78.0 \%$ & $6.5 \%$ & $0.8 \%$ & $14.8 \%$ & $76.3 \%$ & $7.9 \%$ & $1.0 \%$ \\
\hline
\end{tabular}


Figure 9 is the VULCAN IK best estimate plot for $2050 \mathrm{~mL}$ (the first main production level). The results were compared to the observed and measured geometry of a bulk sample drive, driven in March 2005 to provide metallurgical test material. A close match was observed between areas that were difficult to mine and/or to install ground support and the predicted areas of Type 2 and Type 3 material.

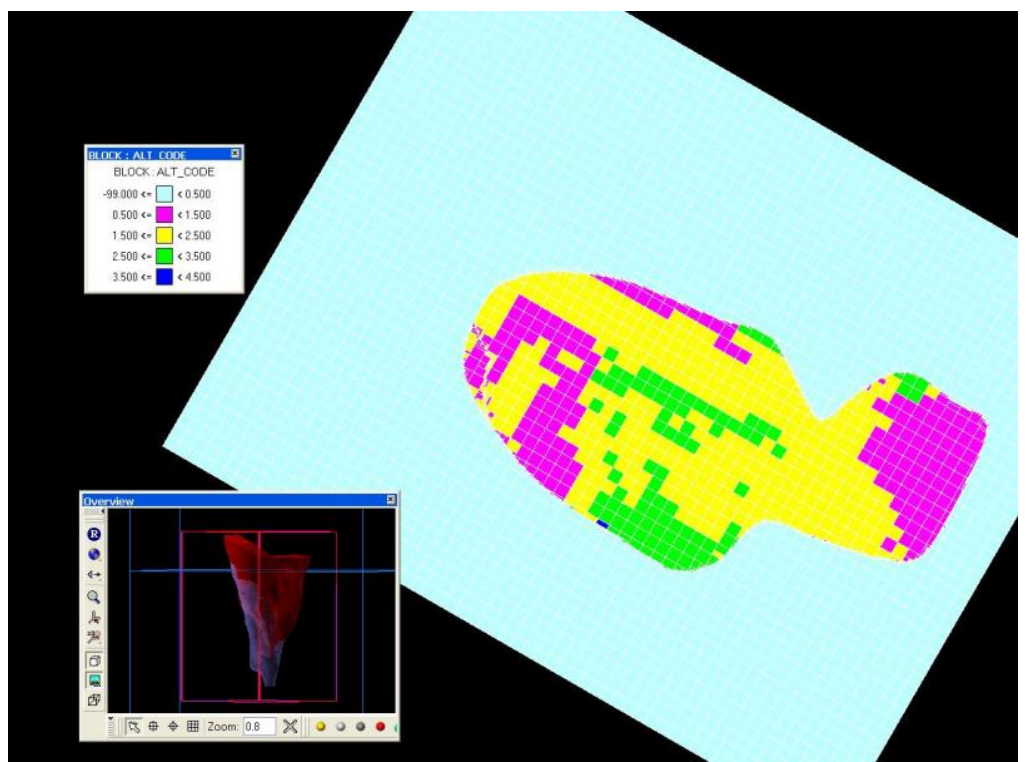

$($ Magenta $=$ Type 1 [good $]$ ground, Yellow $=$ Type 2 [poor $]$ ground, Green $=$ Type 3 [very poor $]$ ground $)$

Figure 9 VULCAN IK best estimate output, $2550 \mathrm{~mL}$

\section{Results application}

Three different support systems were developed for purposes of cost estimation:

- Type A was designed for use in low deformation ground, hence ground in which the assessed magnitude of $\sigma_{\max }$ is predicted to be less than $65 \%$ of the average intact uniaxial compressive strength of the wallrocks (from the results of three-dimensional, global field stress analysis applied to two-dimensional simulations of average excavation cross-section profiles).

- Type B was designed to provide tough but deformable reinforcement for kimberlite drifts in which moderate to high levels of peripheral rock mass deformation are expected, hence in ground where $\sigma_{\max }$ is predicted to be more than $65 \%$ but less than $90 \%$ of the average intact uniaxial compressive strength of the wallrocks.

- Type $\mathrm{C}$ is intended to provide tough, deformable drift reinforcement when severe rock mass deformation is expected or experienced, hence in ground where $\sigma_{\max }$ is more than $90 \%$ of the average intact uniaxial compressive strength of the wallrock.

Application of the three ground support types requires consideration of failure potential, with increasing depth, of each phase 6/7 material type category. If the results are related to the percent frequencies of the material-type categories by production level, as defined by the VULCAN IK results, the percent frequencies by production level of the support categories for each material-type may be defined. The results for each production level then need only to be multiplied by the total planned kimberlite drift development metres, for each planned production level, to enable the weighted, overall usage for each support category to be defined, as suggested by Table 9 . 
Table 9 Weighted average support category requirements, phase 6/7 kimberlite drifts

\begin{tabular}{ccccl}
\hline $\begin{array}{c}\text { Production } \\
\text { Level }\end{array}$ & $\begin{array}{c}\text { Support } \\
\text { Type A }\end{array}$ & $\begin{array}{c}\text { Support } \\
\text { Type B }\end{array}$ & $\begin{array}{c}\text { Support } \\
\text { Type C }\end{array}$ & Comments \\
\hline 2070 & $35 \%$ & $65 \%$ & $0 \%$ & Local minor bottom corner damage possible \\
2050 & $45 \%$ & $55 \%$ & $0 \%$ & Local moderate bottom corner damage possible \\
2030 & $50 \%$ & $50 \%$ & $0 \%$ & Local moderate bottom corner damage possible \\
2010 & $50 \%$ & $40 \%$ & $10 \%$ & Some severe bottom corner damage possible \\
\hline
\end{tabular}

\section{Acknowledgements}

The author wishes to thank all the personnel involved with the Koala Feasibility Study, in particular those who produced the data and information presented here. The author also wishes to acknowledge the permission given by BHP Billiton Diamonds Inc. for publication of this technical paper, as well as the permission given by S. Godden to reproduce summary details of his original work.

\section{References}

Bieniawski, Z.T. (1976) Rock Mass Classification in Rock Engineering. Exploration for Rock Engineering, Z.T. Bieniawski (editor), Vol. 1, Balkema, Rotterdam.

EKATI Diamond Mine (2006) Koala Underground Project, Section 5.1, Feasibility Study June 2006, Technical Report to BHP Billiton Corporate.

Godden, S. (2005) Geotechnical Investigation, Koala Underground Feasibility Study, EKATI Diamond Mines, NWT, Canada, S. Godden and Associates Ltd, consultancy report to BHP Billiton Diamonds' EKATI Mine, November.

Godden, S. (2006) Kimberlite Performance Appraisals, Drift Support Design and Wet Muck Flow Potential, Koala Underground Feasibility Study, EKATI Diamond Mines, NWT, Canada, S. Godden and Associates Ltd consultancy report to BHP Billiton Diamonds' EKATI mine, February.

Goodman, R.E. (1989) Introduction to Rock Mechanics, 2nd Edition Publisher, John Wiley and Sons.

Hoek, E. (1990) Estimating Mohr-Coulomb Friction and Cohesion Values from the Hoek-Brown Failure Criterion, International Journal Rock Mechanics, Mining, Science and Geomechics Abstracts, Vol. 27, No. 3, pp. 227-229.

Hoek, E., Carranza-Torres, C. and Corkum, B. (2002) Hoek-Brown Criterion - 2002 Edition, Proceedings NARMSTAC Conference, Toronto, 1, pp. 267-273.

Obert, L. and Duvall, W.I. (1967) Rock Mechanics and the Design of Structures in Rock, Pub. John Wiley and Sons Inc.

ROCKDATA (1991) A Computer Program to Analyze Laboratory Strength Data, Rock Engineering Group, University of Toronto, Version 2.2.

Rocscience (2002) ROCLAB - Rock Mass Strength Analysis using the Hoek-Brown Failure Criterion, User's Guide.

Shah, S. and Hoek, E. (1992) Simplex Reflection Analysis of Laboratory Strength Data to Obtain Hoek-Brown Parameters, Canadian Geotech. Journal. 